\title{
A preliminary study in osteoinduction by a nano-crystalline hydroxyapatite in the mini pig
}

\author{
Werner Götz ${ }^{1}$, Solvig Lenz ${ }^{2}$, Christoph Reichert ${ }^{1}$, Kai-Olaf Henkel ${ }^{3}$, \\ Volker Bienengräber ${ }^{4}$, Laura Pernicka ${ }^{4}$, Karsten K.H. Gundlach ${ }^{4}$, Tomasz Gredes ${ }^{5}$, \\ Thomas Gerber ${ }^{2}$, Tomasz Gedrange ${ }^{5 *}$, Friedhelm Heinemann ${ }^{6}$
}

\author{
${ }^{1}$ Dept. of Orthodontics, Oral Biology Laboratory, University of Bonn, Dental Hospital, Bonn, Germany \\ ${ }^{2}$ Institute for Physics, Dept. for Materials Research and Nanostructures, University of Rostock, \\ Rostock, Germany \\ ${ }^{3}$ Dept. of Oral and Maxillofacial Surgery, German Military Hospital Hamburg, Hamburg, Germany \\ ${ }^{4}$ Dept. of Craniomaxillofacial Surgery, University of Rostock, Rostock, Germany \\ ${ }^{5}$ Dept. of Orthodontics, Dental Hospital, University of Greifswald, Greifswald, Germany \\ ${ }^{6}$ Dept. of Dental Prosthesis, Gerontostomatology and Medical Materials Science, Dental Hospital, \\ University of Greifswald, Greifswald, Germany
}

\begin{abstract}
To test the probable osteoinductive properties of NanoBone ${ }^{\circledR}$, a new highly non-sintered porous nano-crystalline hydroxylapatite bone substitute embedded into a silica gel matrix, granules were implanted subcutaneously and intramuscularly into the back region of 18 mini pigs. After periods of 5 and 10 weeks as well as 4 and 8 months, implantation sites were investigated using histological and histomorphometric procedures. Signs of early osteogenesis could already be detected after 5 weeks. The later periods were characterized by increasing membranous osteogenesis in and around the granules leading to the formation of bone-like structures showing periosteal and tendon-like structures with bone marrow and focal chondrogenesis. Bone formation was better in the subcutaneous than in the intramuscular implantation sites. This ectopic osteogenesis is discussed with regard to the nanoporosity and microporosity of the material, physico-chemical interactions at its surface, the differentiation of osteoblasts, the role of angiogenesis and the probable involvement of growth factors. The results of this preliminary study indicate that this biomaterial has osteoinductive potential and induces the formation of bone structures, mainly in subcutaneous adipose tissue in the pig.
\end{abstract}

Keywords: Bone graft; bone remodelling; osteogenesis; silica; hydroxyapatite; osteoblast; osteoclast

\section{Introduction}

Autogenous bone is believed to be the gold standard in bone repair. However, bone substitute and grafting biomaterials are becoming increasingly important for all aspects of surgery and dentistry [1-4]. Within the broad range of biomaterials used in craniofacial bone surgery [5], calcium phosphate-based bioceramics, e.g. hydroxyapatite (HA) or $\beta$-tricalciumphosphate $(\beta$-TCP), are the most widely used and considered to be biocompatible, non-immunogenic and osteoconductive [57]. However, due to high temperature sinter-

Corresponding: Prof. Dr. Tomasz Gedrange

Tel. +49-(0)3834-86-7110 Fax: +49-(0)3834-86-7113

E-mail: gedrange@uni-greifswald.de ing during processing, the material density may be increased and the porosity decreased. These factors negatively influence osteoconductivity and resorption at the implantation site. These bioceramics may therefore have a longer degradation time and even induce chronic inflammatory processes [5]. Recently, a granular material consisting of nanocrystalline HA embedded in a silica gel matrix [8] with an extremely large internal surface and a material porosity of about $60 \%$ [9] has been developed and approved. Animal experiments using this nanocrystalline HA (ncHA) in the mini pig critical size defect model showed a significantly higher rate of bone formation compared to other HA and TCP materials or gelatine sponges and a nearly complete resorption 8 months after implantation $[10,11]$ giving an initial insight into the cellular 
processes of osteoconduction and early remodelling in vivo [11-14]. Furthermore, the recruitment and occurrence of Runx-2-positive osteoblast precursor cells and the upregulation of BMP-2 in sites grafted by the ncHA in humans suggests that this material has osteoinductive properties [13]. Osteoinduction is defined as the process of recruiting and differentiating mesenchymal stem cells from the surrounding host into bone or cartilage $[15,16]$. Generally, it is believed that osteoinduction is mediated by inductive substances like bone morphogenetic proteins (BMPs), a biological process which has been shown to occur in decalcified bone [17]. However, to determine osteoinduction, a given material has to show ectopic ossification after implantation into non-osteogenic sites such as skeletal muscle or subcutaneous tissue [18]. To prove the hypothetic osteoinductive properties of the ncHA, subcutaneous and intramuscular implantation experiments using the mini pig model was carried out.

\section{Materials and Methods}

Animal experiments. All animal handling and surgical procedures were approved by the local committee for experimental animal research ethics and conducted according to the European Community guidelines for the use and care of laboratory animals. 18 oneyear-old female Goettingen mini pigs (Ellegaard, Dalmose, Denmark) with an average weight of $20-25 \mathrm{~kg}$ were used and kept in the Animal Facility Dept. of the University of Rostock. All surgical procedures were performed under general anesthesia. After intramuscular pre-medication with $1 \mathrm{mg}$ atropinum sulfuricum (Eifelfango ${ }^{\circledR}$, Bad Neuenahr, Germany) and $5 \mathrm{~g} / \mathrm{kg}$ azaperon (Stresnil@, Jenssen-Cilag, Neuss, Germany), the animals were anesthetized intramuscularly with ketamine hydrochloride (Ketamin, Belapahrm, Vercha, Germany) and $0.2 \mathrm{mg} / \mathrm{kg}$ midazolam hydrochloride (Dormicum, Hoffmann - La Roche, GrenzachWylen, Germany). Each animal received one subcutaneous and one intramuscular implantation through one incision wound. After incision of cutis, subcutis and muscular fascia in the neck region, $0.1 \mathrm{ml}$ of NanoBone ${ }^{\circledR}$ (Artoss, Rostock, Germany) granulate were implanted into the trapezius muscle and subcutaneous adipose tissue at the level of the spinous process of the 6th cervical vertebra. Implantation areas were marked with animal marker ink (H. Hauptner \& Richard Heberholtz, Solingen, Germany) during surgery. After implantation, the wound was closed by layer suture (Ethicon ${ }^{\circledR}$, Norderstedt, Germany; Catgut, Markneuenkirchen, Germany). The animals received $5 \mathrm{ml}$ Terramycin ${ }^{\circledR}$ (Pfizer AG, Karlsruhe, Germany) as postoperative antibiotics.

3 animals each were sacrificed at 5 weeks, 10 weeks and 4 months after implantation and 9 animals 8 months after implantation by intracardiac injection of $8 \mathrm{ml}$ Eutha77 ${ }^{\circledR}$ (Essex Pharma, München, Germany) after premedication in compliance with anesthesia. For sample fixation without size changes implants with surrounding tissues were harvested and fixed in $4 \%$ paraformaldehyde in $0.1 \mathrm{M}$ phosphate buffer saline solution [19].

Histology. All subcutaneous and muscle specimens were processed and prepared for grinding sections. Specimens from two 4-month and three 8-month-old animals were also subdivided for additional paraffin histology.

Grinding technique. After fixation in $4 \%$ buffered formaldehyde and dehydration with ascending ethanol and 2-hydroxyethyl- methacrylate (GMA) concentrations, the specimens were processed according to the sawing and grinding technique (Donath and Breuner 1982). An ultraviolet light-activated polymethylmethacrylate (PMMA; Technovit $7200^{\circledR}$ VLC, Heraeus Kulzer, Wehrheim, Germany) was used as the infiltration medium. Embedding in a 1:1 combination of GMA and the embedding medium for 5 days was followed by $100 \%$ embedding in the embedding medium. After penetration of the whole specimen with the embedding medium, Technovit 7200 VLC $^{\circledR}$ was carefully photopolymerized. Parallel sections 100 to $200 \mu \mathrm{m}$ thick were cut from the specimens in a microsawing machine (ETS ${ }^{\circledR}$, Exakt, Norderstedt, Germany) in different directions. The desired final thickness of the specimens $(10-20 \mu \mathrm{m})$ was obtained by using a microgrinding system $\left(\mathrm{EMS}^{\circledR}\right.$, Exakt, Norderstedt, Germany). Grindings were stained with toluidine blue, Goldner's trichromic stain or von Kossa stain.

Paraffin histology. After fixation, specimens were decalcified in neutral 10\% ethylene diamine tetra-acetic acid (EDTA) and processed for paraffin histology as recently described [20]. Selected sections were stained with H.E.

Histomorphometry. The slices or grindings were scanned (Agfa Horizon Ultra ${ }^{\circledR}$, Agfa, Köln, Germany) for documentation and histomorphometric evaluation. The original images were prepared for histomorphometric analysis using Adobe Photoshop ${ }^{\circledR}$ software 6.0. The area where Nanobone ${ }^{\circledR}$ granules could be localized was defined as a region of interest (ROI) and completely colored in light blue. Corresponding to this ROI, a second pseudo-color image of the same area was created in which the area of bone was colored with red and the area of biomaterial with yellow. These pseudo-color images were analyzed using AnalySIS ${ }^{\circledR}$ software (Münster, Germany). This analysis calculated the bone and biomaterial content as a percentage of the ROI. The histomorphometric evaluation gave the percentage of bone, Nanobone ${ }^{\circledR}$ biomaterial and soft tissue per ROI. 33 slides were analyzed (16 stained with toluidine blue and 17 with Goldner's trichrome stain) for subcutaneous and 39 slides (15 stained with toluidine blue and 24 with Goldner's trichrome stain) for muscular tissue. No statistical evaluation was done as the varying number of specimens and resulting slices which were available for the histomorphometrical analyses would have meant the validity of the obverse data would have been doubtful.

\section{Results}

\section{Macroscopy}

After preparation, bony tissues were palpable in the subcutaneous region of all 10 -week and 4-month-old animals and in 4 of the 8-month-old animals, but never within the muscles. However, all former transplantation sites were excised in toto on a large scale.

\section{Histology}

5 weeks. Aggregations of undegraded ncHA granules ensheathed by a connective tissue capsule were detectable in the implantation sites of all animals (Fig. 1a). The matrix of the granules had porosities of various sizes. The intergranular connective tissue appeared loose and contained vessels and fibroblasts subcutaneously (Figs. 1a-d), but was more fibrous and collagenous in the muscles. All granules were covered by multinucleated giant cells probably representing osteo- 

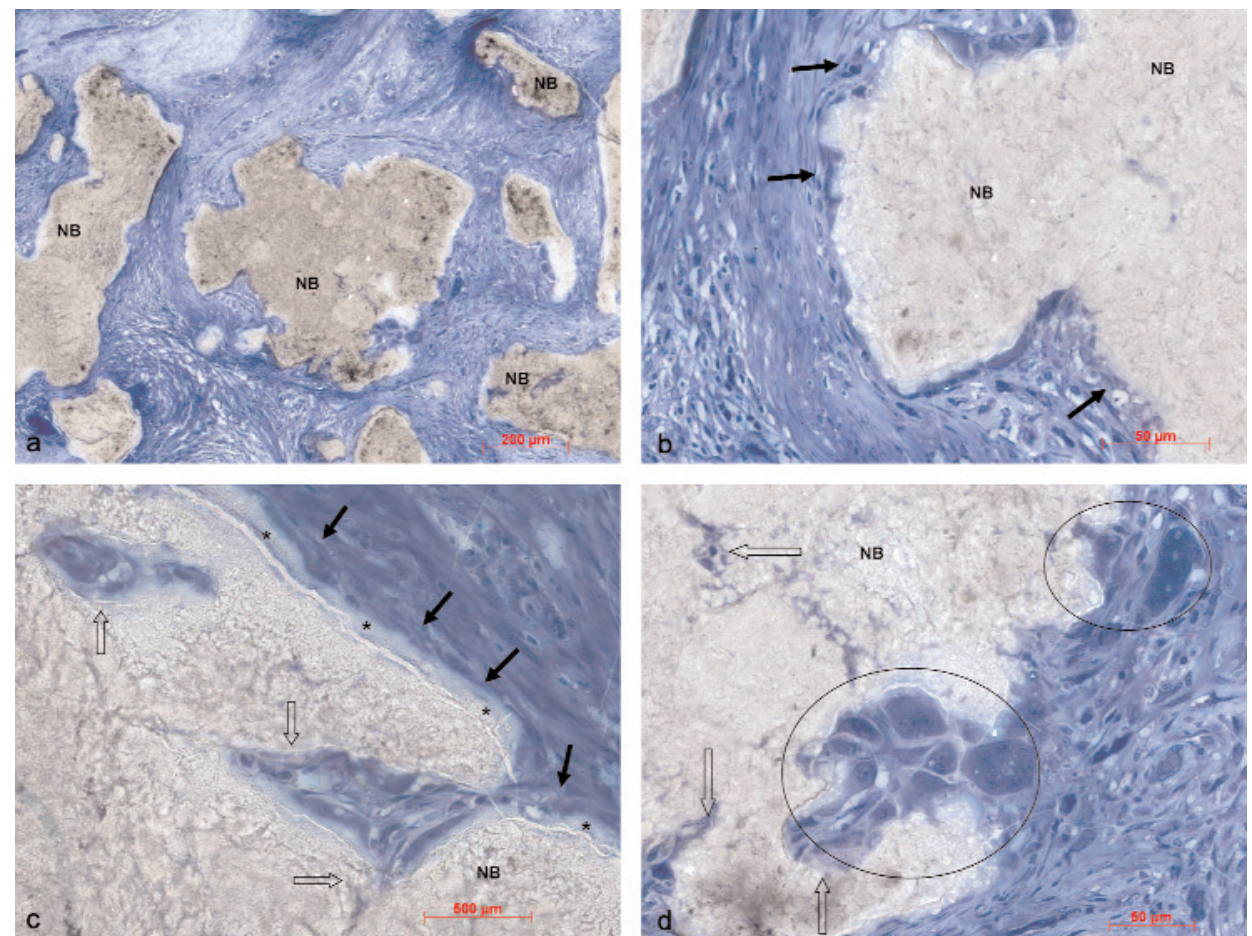

Fig. 1. Histology, 5-week old animals, subcutaneous (s.c.) specimens, grinding sections. a. Aggregations of undegraded Nano Bone ${ }^{\circledR}(\mathrm{NB})$ granules $(\mathrm{NB})$ within intergranular connective tissue, toluidine blue (tb) stain, original magnification $\times 10$; b. Undegraded NB granule covered by osteoblasts (black arrows); tb stain, $\times 20$; c. NB granule covered by osteoblasts (black arrows), small osteoid seam (black asterisks), open arrows $=$ fibrovascular extensions; tb stain, $\times 40$; d. Accumulations of osteoclasts (circled) on the surface of NB granules, open arrows = fibrovascular extensions; tb stain, $\times 40$. clasts (Fig. 1d). In two of the three animals, osteoblastlike cells identified by a longish or cuboidal phenotype on the outer surface of the granules were apparent (Figs. 1b, c). Under these osteoblasts, a thin osteoid could be seen, thus representing early desmal osteogenesis (Fig. 1c). Few isolated cells and small fibrovascular extensions or protrusions as well as few vessellike structures were cut focally within the granules (Figs. 1c, d). Surfaces not covered by osteoblasts were populated by osteoclasts (Fig. 1d).

10 weeks. Neither ncHA granules nor bone tissue were detectable in the muscle implantation sites. Specimens from subcutaneous implantation sites of all three pigs showed increased osteogenesis (Fig. 2a). Small bony spiculae and larger bony trabeculae which partly had begun to coalescence had developed around and within thegranules (Fig. 2b). In contrast to the 5-week specimens, the number and size of the granules was decreased indicating increased degradation. The intergranular connective tissue now appeared highly cellular and vascularized. Single granules were partly covered by osteoid or by newly formed woven bone (Figs. $2 \mathrm{~b}, \mathrm{c}$ ) and populated by seams of osteoblasts indicating active form of matrix secretion (Figs. 2b, c). Intragranular finger-like and vessel-containing interconnecting protrusions as well as single cells or vessels surrounded by osteoid were cut. . Focally, mineralization fronts within the osteoid matrix and incorporation of osteoblasts to become osteocytes were visible (Fig. 2c). Larger areas of mineralized bone were also already visible (Fig. 2d). ,Areas with increased osteo- genesis were characterized by a clearly visible metachromatic cement line in toluidine blue-stained specimens. On the granules' surfaces as well as on newly formed bone, osteoclasts were cut. Typically, an osteoblastic and an osteoclastic compartment could be observed. In sections from the specimen of one animal of the 10 weeks group, newly formed bone occupied a larger area than in the other animals. Bony trabeculae were partly arranged in a parallel manner and focally transformed into a lamellar bone structure. In these areas, osteocytes were visible within lacunae as were Haversian-like canals (Fig. 2d). NcHA residues were incorporated into bone.

4 months. In the subcutaneous implantation sites, osteogenesis in 2 animals was in a very advanced stage, while there was no or only minor osteogenesis in the skeletal muscle. In one of them, the newly formed bone had a more compact structure (Fig. 3a), in the other it appeared as if a long bone had been cut transversally with a central cancellous structure surrounded by a compact cortical structure. This cortex was covered by a layer of connective tissue resembling a periost. In both cases, the bony tissues appeared as woven bone with some lamellar areas and cement lines. Osteocytes, Haversian-like canals, osteoblast seams with underlying osteoid and osteoclasts were frequent (Fig. 3a, d). Residues of the ncHA granules had been incorporated into the bone. A further peculiarity in both cases concerned the arrangement of the interbecular and peritrabecular connective tissue: Focally, bundles of tight collagenous connective tissues had an undulating appear- 

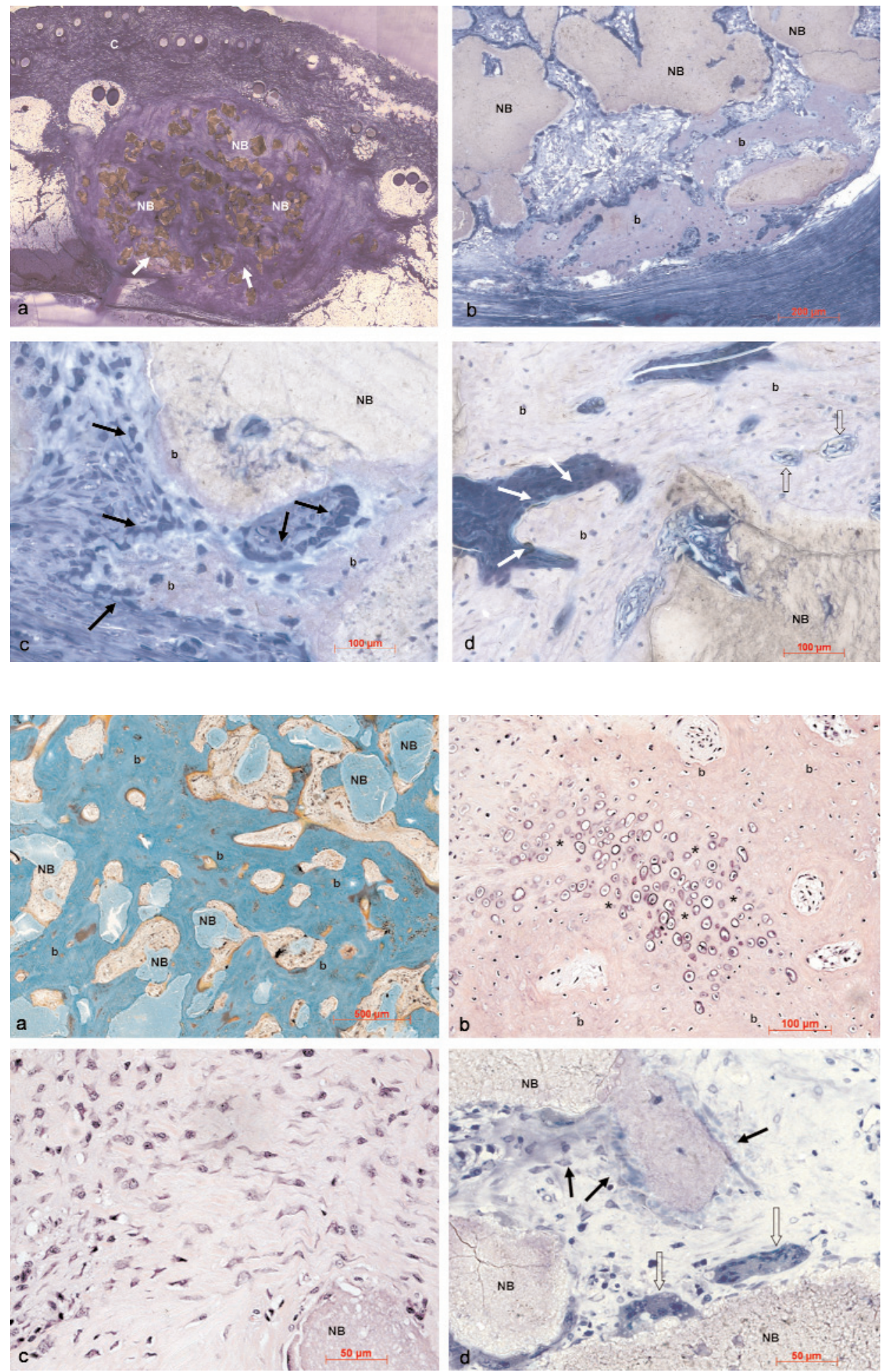

Fig. 2. Histology, 10-week old animals, s.c. specimens, grinding sections. a. Implantation site within s.c. adipose tissue beneath cutis (c), undegraded NB granules with foci of early osteogenesis (white arrows); tb stain, $\times 1.25$; b. Same specimen as in $b$, undegraded NB granules covered by osteoclasts surrounded by newly formed bone (b) covered by osteoblasts; tb staining, $\times 10$; c. Newly formed, mineralizing bone substance (b) containing embedded osteocytes deposited on the surface of NB granules covered by osteoblasts (black arrows); tb stain, $\times 40$; d. 10-week old animal with increased osteogenesis, large bony trabeculae (b) containing osteocytes and Haversian channel-like structures (open arrows), white arrows: osteoblasts, NB= NanoBone ${ }^{\circledR}$ granule; tb stain, $\times 20$.

Fig. 3. Histology, 4-month old animals, s.c. specimens. a. Grinding section, advanced osteogenesis forming cancellous bone structure (b), residues of $\mathrm{NB}$ granules; trichromic stain (tc), $\times 5$; b. Paraffin section, cartilagineous structure (black asterisks) within newly formed bone (b); H.E. stain, $\times 40$; c. Paraffin section, tendon like structure with longish fibroblasts near newly formed bone, $\mathrm{NB}=$ NanoBone ${ }^{\circledR}$ granule; H.E. staining, $\times 40$; d. Grinding section; large osteoclasts (open arrows) on the surface of a NB granule, osteoblasts (black arrows) secreting bone matrix (b); tb stain, $\times 40$. ance and blended into bone. Longitudinally cut or ground, longish extended fibroblasts looking like tendinocytes were intermingled (Fig. 3c). A cartilagelike structure consisting of single chondrons within a fibrous interterritorial matrix could also be observed in one animal. ,Chondrocytes in the center resembled hypertrophic chondrocytes (Fig. 3b).
8 months. In 4 of the 9 animals investigated, advanced subcutaneous osteogenesis was visible microscopically (Fig. 4), while undegraded agglomerates of the ncHA granules could be observed in the others. In one pig, bony pieces had also developed intramuscularly. In 3 cases spongy bone, in one case compact bone had developed. The cancellous bone 


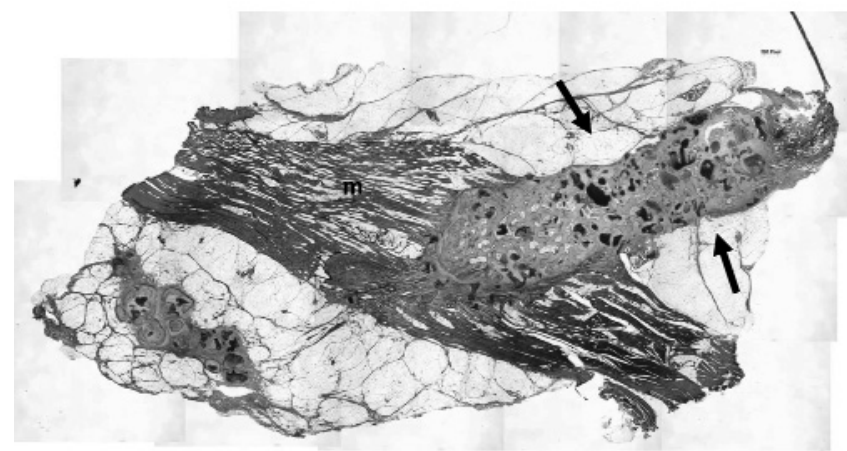

Fig. 4. Histology, 8-month old animal, grinding section, large cancellous bony ossicle (black arrows) developed in the s.c. space and extending into a superficial muscle bundle (m), residues of NB granules (red asterisks); tb stain, $\times 1,25$.

formation was partly bordered by a cortical collar (Fig. 5a-d). Focally, a periost-like connective tissue covered the bones (Fig. 5d). In one case, skeletal muscle fibres probably running from deeper layers into the subcutaneous region inserted into this periost-like sheath (Fig. 5d). The structure of the bone was mostly of the woven type, but lamellar areas with an osteon-like appearance could also be seen (Fig. 5b). Residues of the bone substitute were intermingled into the bone tissue (Figs. 5a, b, d). In some cases, there were also undegraded granules outside the bone area in the periosseous connective tissue. Some of the granules showed signs of osteogenesis. In the center of the bony pieces between the trabeculae, loose vascularized connective or adipose tissues resembling bone marrow were to be seen (Fig. 5).

\section{Histomorphometry (Fig. 6)}

5 weeks. The amount of biomaterial was quantified in subcutaneous tissue with $25.6 \%( \pm 2.3)$ and in muscle with $20.3 \%( \pm 11.2)$. The percentage of soft tissue amounted to $74.4 \%( \pm 2.3)$ in subcutaneous tissue and to $79.7 \%( \pm 11.2)$ in muscle. As described above, only osteoid and no mineralized bone was detectable.

10 weeks. The mean value was $17.8 \%( \pm 6.0)$ biomaterial, $2.2 \%( \pm 1.5)$ new bone and $80.1 \%( \pm 6.9)$ soft tissue subcutaneously. As already outlined, neither NanoBone ${ }^{\circledR}$ nor bony tissue were found intramuscularly in these animals.

4 months. NanoBone ${ }^{\circledR}$ amounted to $6.0 \%( \pm 1.6)$, newly formed bone to $53.3 \%( \pm 23.7)$ and soft tissue to $40.7 \%( \pm 22.6)$ in subcutaneous tissues. Appreciably more NanoBone ${ }^{\circledR}(16.2 \% \pm 3.2)$ was detectable in muscle. Here, the percentage of newly formed bone amounted to $12.4 \%( \pm 13.3)$ and the percentage of soft tissue to $71.4 \%( \pm 13.3)$.

8 months. The histomorphometry results were as follows: $10.8 \%( \pm 4.0)$ NanoBone $^{\circledR}, 47.5 \%( \pm 13.6)$ new bone and $41.7 \%( \pm 11.6)$ soft tissue for subcutaneous implantation sites. $19.2 \%( \pm 7.6)$ of NanoBone ${ }^{\circledR}, 11.2$
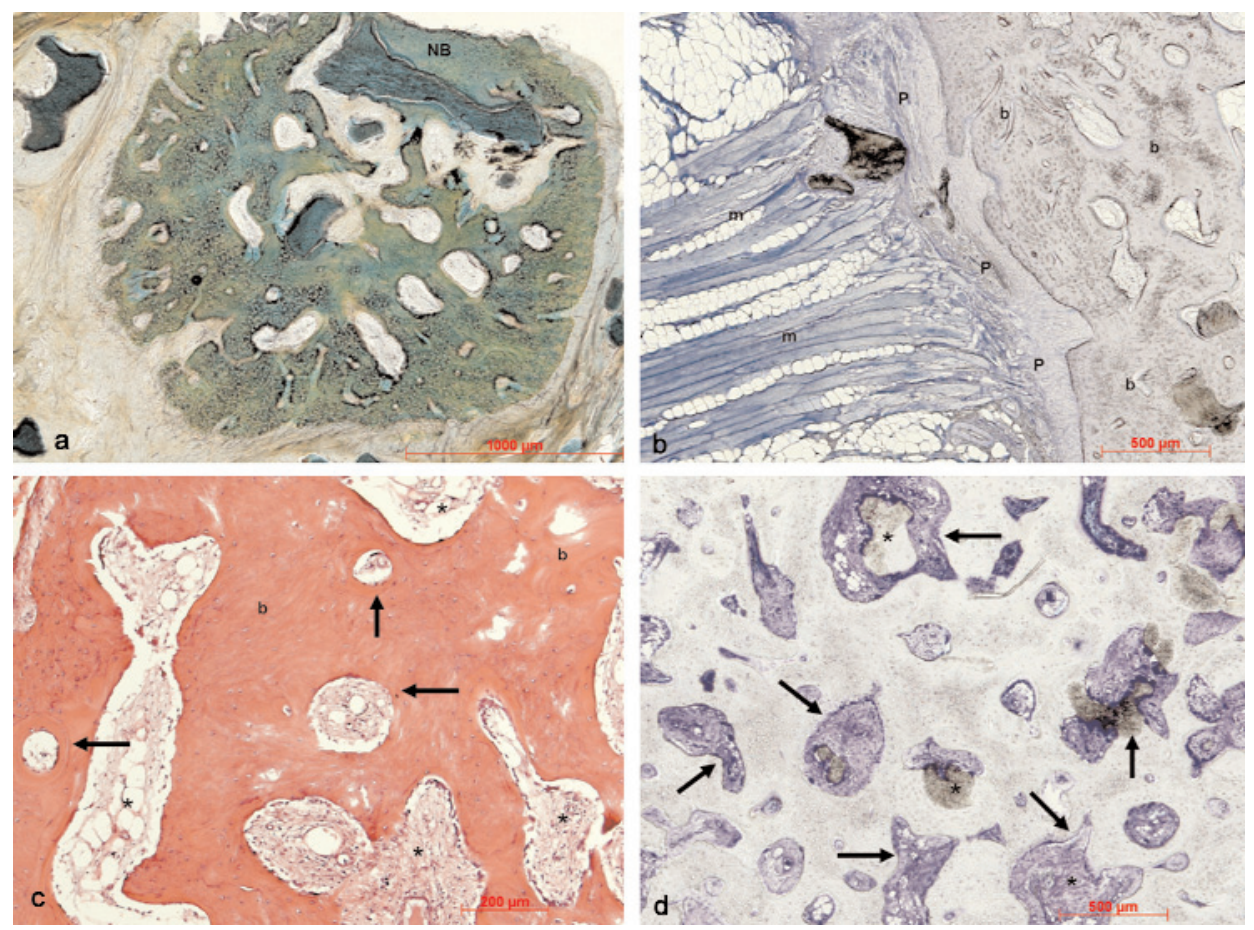

Fig. 5. Histology, 8-month old animals, s.c. specimens. a. Grinding section, transversally cut ossicle consisting of cancellous bone (b), rests of NB granules; tc stain, $\times 5$; b. Grinding section, newly formed nearly cancellous bone with perforating channels containing connective tissue (black arrows), black asterisks: small NB rests; tb stain, $\times 5$; c. Paraffin section, newly formed cancellous fibrous bone tissue (b) with remodelling into lamellar osteons (black arrows), intertrabecular connective and adipose marrow-like tissue (black asterisks); H.E. stain, $\times 10$; d. Grinding section, muscle fibers (m) inserting via periost-like structure (p) into subcutaneously newly formed bone (b), white asterisk = small NB rests; tb stain, $\times 5$. 

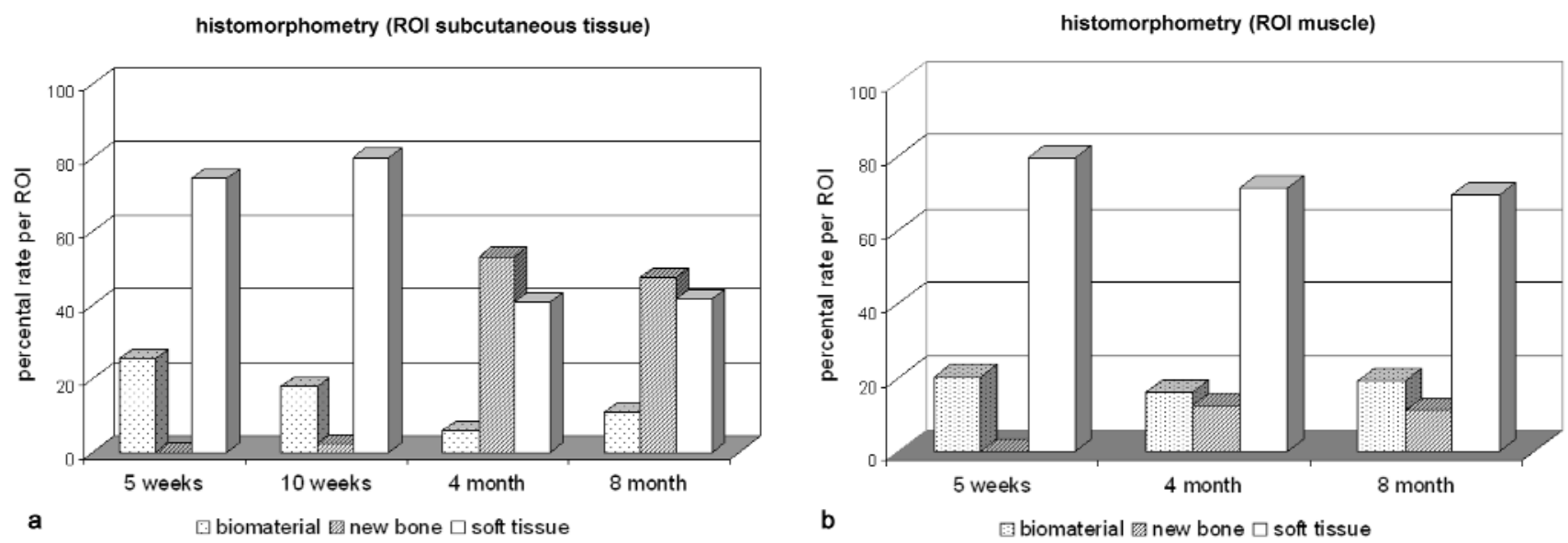

Fig. 6. Histomorphometric findings in subcutaneous (a) and muscle (b) implantation sites for bone, biomaterial (NanoBone $\left.{ }^{\circledR}\right)$ and soft tissue areas, $\mathrm{ROI}=$ regions of interest.

$\%( \pm 19.1)$ of newly formed bone and $69.6 \%( \pm 17.0)$ was measured in muscle.

\section{Discussion}

The bone substitute tested in this study represents a new degradable nanoporous bone grafting material consisting of synthetic nanocrystalline HA embedded in a porous silica gel matrix $[8,9,11]$. Histological and immunohistochemical findings obtained after implantation in mini pig jaws and findings in bone biopsies taken from patients after implementation for jaw augmentation revealed its osteoconductive nature and early remodeling in the host $[11,13,20]$. The appearance of osteoblast precursor cells and the upregulation of BMP-2 also indicated probable osteoinductive features $[13,20]$. To evaluate the osteoinductive capacities of the material, it was tested after ectopic subcutaneous and intramuscular implantation in the mini pig. In this animal model, signs of early osteogenesis were seen histologically after just 5 weeks of implantation. This is earlier than described after ectopic calcium phosphate implantation in the pig, where osteogenesis appeared after 45 days intramuscularly and 60 days subcutaneously [21, 22]. Early osteogenesis was revealed by the observation of osteoblast-like cells and osteoid seams on the surface of the ncHA granules and fibrovascular extensions and vessel-like structures penetrating the biomaterial. From a descriptive point of view, the early events observed in ectopic ncHA osteogenesis are similar to those described for osteoinduction by synthetic calcium phosphate ceramics in sheep, dogs, goats and pigs histologically [21, 23, 24]. How materials induce the very first stages of osteogenesis is still a matter of debate [25]. Physico-chemical interactions with the material surface such as dissolution and reprecipitation, e.g. of carbonate ions with proteins, are seen as important [26,27]. Furthermore, the early and late stages of osteogenesis in bone substitutes like cell or vessel invasion depend on the micro and macro porosities of the material [26, 27]. Recent investigations into osteogenesis after augmentation by using the ncHA biomaterial in animals and humans have demonstrated that the different porosity dimensions ranging between $\mu \mathrm{m}$ and $\mathrm{mm}$ may promote these processes $[11-13,20]$.

In the study presented, osteogenesis increased qualitatively and quantitatively and mineralized bone could thus be detected histologically and morphometrically after 10 weeks. Woven bone had developed on the surface of and within the granules. In one animal, larger bony trabeculae consisting of lamellar bone with osteocytes and Havers' channels were already to be seen. These findings show that after subcutaneous implantation of the ncHAdesmal osteogenesis occurs as is the case for heterotopic osteoinduction by demineralized bone or calcium phosphate ceramics [17, $28]$. According to recent findings from previous animal experiments and human testing [13, 20,29], multinucleated osteoclasts were identified as cells populating implanted ncHA granules and also participating in remodeling the newly formed bone. These findings in the ectopic implantation situation support the view that this biomaterial is specifically degradaded by osteoclasts and that it is later integrated into the physiological remodeling processes of the host organism [13]. Osteoclastic resorption was observed for all stages investigated revealing continuous but not excessive degradation the ncHA. Faster degradation leading to the destruction of the biomaterial geometry may be a risk for osteoinduction [30]. The later development of the bony structures formed around the granules was characterized histomorphometrically by a strong increase of newly formed bone and histologically by 
remodeling of the originally formed woven bone into mature lamellar bone. The bony formations developed after 4 and 8 months even showed outer cortical and inner cancellous trabecular structures containing bone marrow and were covered by a periost-like structure. A tendon-like structure extending to the bony surface was also observed in a 4-month-old animal. There are few descriptions or discussions of such well-developed structures arising from ectopic bone formation in the relevant literature. However, Kondo et al. [31] observed the development of bone marrow within bony structures after $\beta$-TCP implantation in the dog dorsal muscles after 4 to 6 months. Obviously, in the experiment presented here, bone formation and differentiation was much better in the subcutaneous than intramuscular area, although we also discuss the fact that subcutaneous tissue may be less osteoinductive than skeletal muscle [32]. However, there are also several reports on failing osteoinduction within back muscles, e.g. in the rabbit [33]. Biomechanical conditions should be considered as one possible reason for this finding: micromovements between the ncHA granules may be more likely in the muscular implant bed than subcutaneously. This can lead to impairment of ectopic osteogenesis or to the deposition of only small amounts of bone around the periphery of the granules.

\section{Conclusion}

The results obtained after ectopic implantation of a highly porous nanocrystalline bone substitute into the mini pig showed early signs of osteogenesis and the later development of bone-like structures, mainly at subcutaneous adipose tissue sites. Because of these findings, this ncHA biomaterialfulfills the conditions which are said to be responsible for the osteoinductive capacities of calcium phosphate bioceramics, namely a low sintering temperature and a high porosity. However, due to the small sample size and the mainly qualitative evaluation of this study, further experiments are necessary to obtain a larger database.

Acknowledgments: This research was partly funded by the German Federal Ministry of Education and Research (BMBZ 01EZ0729). The authors would like to thank Mrs. I. Müller-Bay, D. Gütschow and S. Niemierski for technical assistance.

\section{References}

[1] Cutter CS, Mehrara BJ. Bone grafts and substitutes. J Long Term Eff Med Implants. 2006;16:249-260.

[2] Kokubo T. Bioceramics and their clinical applications. In: ed. Cambridge: Woodhead Publishing Ltd; 2008.

[3] Sutherland D, Bostrom M. Grafts and bone graft substitutes. In: Liebermann JR, Friedlaender GE, ed. Bone regeneration and repair. Biology and clinical application. Totow: Humana Press; 2005:133.
[4] Zietek M, Gedrange T, Mikulewicz M. Long term evaluation of biomaterial application in surgical treatment of periodontosis. J Physiol Pharmacol. 2008;59 Suppl 5:81-86.

[5] Abukawa H, Papadaki M, Abulikemu M et al. The engineering of craniofacial tissues in the laboratory: a review of biomaterials for scaffolds and implant coatings. Dent Clin North Am. 2006;50:205-216, viii.

[6] Barrere F, van Blitterswijk CA, de Groot K. Bone regeneration: molecular and cellular interactions with calcium phosphate ceramics. Int J Nanomedicine. 2006;1:317-332.

[ 7] Ruhé PQ, Wolke JG, Spauwen PH, Jansen JA. Calcium phosphate ceramics for bone tissue engineering. In: Bronzino JD, ed. Engineering and artificial organs (The biomedical engineering handbook). Boca Raton, London, New York: Taylor and Francis; $38.31-38.18$.

[ 8] Gerike W, Bienengraber V, Henkel KO et al. The manufacture of synthetic non-sintered and degradable bone grafting substitutes. Folia Morphol (Warsz). 2006;65:54-55.

[ 9] Gerber T, Traykova T, Henkel KO, Bienengraber V. Development and in vivo test of sol-gel derived bone grafting materials. J Sol Gel Sci Techn. 2003;26:11731178.

[10] Henkel KO, Gerber T, Dorfling P, Gundlach KK, Bienengraber V. Repair of bone defects by applying biomatrices with and without autologous osteoblasts. J Craniomaxillofac Surg. 2005;33:45-49.

[11] Henkel KO, Gerber T, Lenz S, Gundlach KK, Bienengraber V. Macroscopical, histological, and morphometric studies of porous bone-replacement materials in minipigs 8 months after implantation. Oral Surg Oral Med Oral Pathol Oral Radiol Endod. 2006;102:606-613.

[12] Bienengraber V, Gerber T, Henkel KO et al. The clinical application of a new synthetic bone grafting material in oral and maxillofacial surgery. Folia Morphol (Warsz). 2006; $65: 84-88$

[13] Gotz W, Gerber T, Michel B et al. Immunohistochemical characterization of nanocrystalline hydroxyapatite silica gel (NanoBone(r)) osteogenesis: a study on biopsies from human jaws. Clin Oral Implants Res. 2008;19:1016-1026.

[14] Heinemann F, Mundt T, Biffar R, Gedrange T, Gotz W. A 3year clinical and radiographic study of implants placed simultanously with maxillary sinus floor augmentations using a new nanocrystalline hydroxyapatite. $J$ Physiol Pharmacol. 2009;60 Suppl 8.

[15] Albrektsson T, Johansson C. Osteoinduction, osteoconduction and osseointegration. Eur Spine J. 2001;10 Suppl 2:S96-101.

[16] De Bruijn JD, Shankar K, Yuan H, Habibovic P. Osteoinduction and its evaluation. In: Kokubo T, ed. Bioceramics and their clinical applications. Cambridge: Woodhead Publishing Ltd; 2008:199.

[17] Solheim E. Osteoinduction by demineralised bone. Int Orthop. 1998;22:335-342.

[18] Ripamonti U, Van den Heever B, Van Wyk J. Expression of the osteogenic phenotype in porous hydroxyapatite implanted extraskeletally in baboons. Matrix. 1993;13:491-502.

[19] Gedrange T, Mai R, Mack F et al. Evaluation of shape and size changes of bone and remodelled bone substitute after different fixation methods. J Physiol Pharmacol. 2008;59 Suppl 5:87-94.

[20] Gerber T, Holzhuter G, Gotz W et al. Nanostructuring of biomaterials - a pathway to bone grafting substitute. Eur J Trauma. 2006;32:132-140.

[21] Yang Z, Yuan H, Tong W et al. Osteogenesis in extraskeletally implanted porous calcium phosphate ceramics: variability among different kinds of animals. Biomaterials. 1996;17:2131-2137.

[22] Gedrange T, Mai R, Weingaertner J et al. Finite element representation of bone substitute remodelling in the jaw bone. Biomed Tech (Berl). 2008;53:220-223. 
[23] Le Nihouannen D, Daculsi G, Saffarzadeh A et al. Ectopic bone formation by microporous calcium phosphate ceramic particles in sheep muscles. Bone. 2005;36:1086-1093.

[24] Yang ZJ, Yuan H, Zou P et al. Osteogenic responses to extraskeletally implanted synthetic porous calcium phosphate ceramics: an early stage histomorphological study in dogs. $J$ Mater Sci Mater Med. 1997;8:697-701.

[25] Knabe C, Ducheyne P. Cellular response to bioactive ceramics. In: Kokubo T, ed. Bioceramics and their clinical applications. Cambridge: Woodhead Publishing Ltd; 2008:133.

[26] Habibovic P, Sees TM, van den Doel MA, van Blitterswijk CA, de Groot K. Osteoinduction by biomaterials--physicochemical and structural influences. J Biomed Mater Res A. 2006;77:747-762.

[27] Habibovic P, Yuan H, van der Valk CM et al. 3D microenvironment as essential element for osteoinduction by biomaterials. Biomaterials. 2005;26:3565-3575.

[28] Ripamonti U. Osteoinduction in porous hydroxyapatite implanted in heterotopic sites of different animal models. Biomaterials. 1996;17:31-35.
[29] Rumpel E, Wolf E, Kauschke E et al. The biodegradation of hydroxyapatite bone graft substitutes in vivo. Folia Morphol (Warsz). 2006;65:43-48.

[30] Bodde EW, Cammaert CT, Wolke JG, Spauwen PH, Jansen JA. Investigation as to the osteoinductivity of macroporous calcium phosphate cement in goats.J Biomed Mater Res B Appl Biomater. 2007;83:161-168.

[31] Kondo N, Ogose A, Tokunaga K et al. Osteoinduction with highly purified betatricalcium phosphate in dog dorsal muscles and the proliferation of osteoclasts before heterotopic bone formation. Biomaterials. 2006;27:4419-4427.

[32] Habibovic P, de Groot K. Osteoinductive biomaterials--properties and relevance in bone repair. J Tissue Eng Regen Med. 2007;1:25-32.

[33] Kurashina K, Kurita H, Kotani A, Takeuchi H, Hirano M. In vivo study of a calcium phosphate cement consisting of alpha-tricalcium phosphate/dicalcium phosphate dibasic/tetracalcium phosphate monoxide. Biomaterials. 1997;18:147-151. 